\title{
5.7 SOME NEW RESULTS IN THE INVESTIGATION OF THE MIDDLE ATMOSPHERE FROM SPACE USING THE DAYTIME HORIZON SCANNING METHOD
}

\author{
R. Room, K. Eerme, and U. Veismann \\ Institute of Astrophysics and Atmospheric Physics \\ 20244 Tartu, Estonia, USSR
}

The results of the restoration of the optical parameters of the El Chichon aerosol cloud at $\lambda 2.2 \mu \mathrm{m}$ are presented. The eight-channel teleradiometer FAZA for visible and nearinfrared spectral regions is described in some detail. Mathematical aspects of data processing for the ill-posed problems are discussed. The results of the restoration of the volume emission rate of the molecular oxygen on $\lambda 1.27 \mu \mathrm{m}$ in the middle atmosphere and of the aerosol on $\lambda$ $0.84 \mu \mathrm{m}$ are presented.
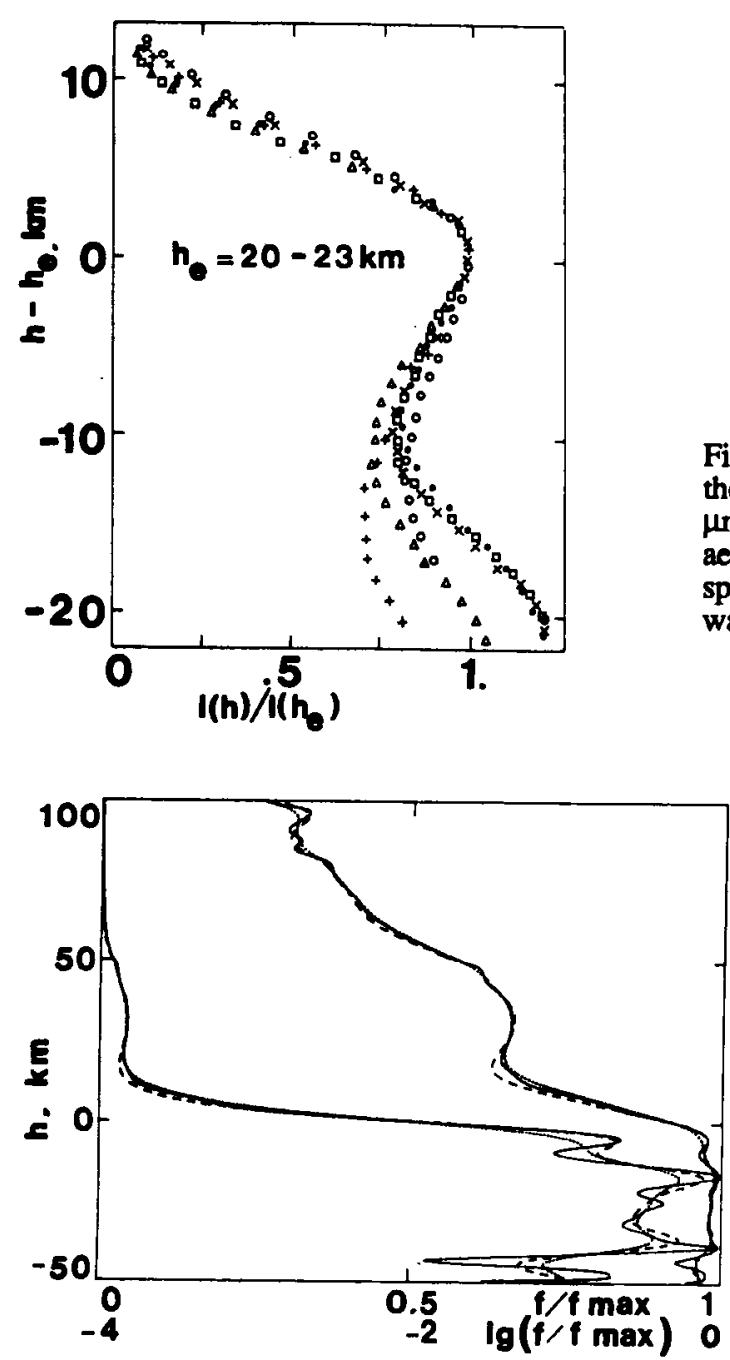

Figure 1. The daytime horizon radiance above the Sahara, 6 July 1982 at the wavelength 2.2 $\mu \mathrm{m}$ in relative units. $h_{e}$ - the height of the acrosol-caused radiance maximum in the stratosphere. The stratospheric acrosol layer at the wavelength $2.2 \mu \mathrm{m}$ has the optical thickness 0.04 .

Figure 2. The modeling of the smooth and restoration processes. The standard deviation of the field response function of the teleradiometer is $3.0 \mathrm{~km}$. The continuous line presents the nonsmoothed, the dotted line the smoothed and the dashed line the restored radiance of the daytime horizon. The left-hand curves are in the linear scale. The right-hand lines present the same curves, but in the logarithmic scale. 


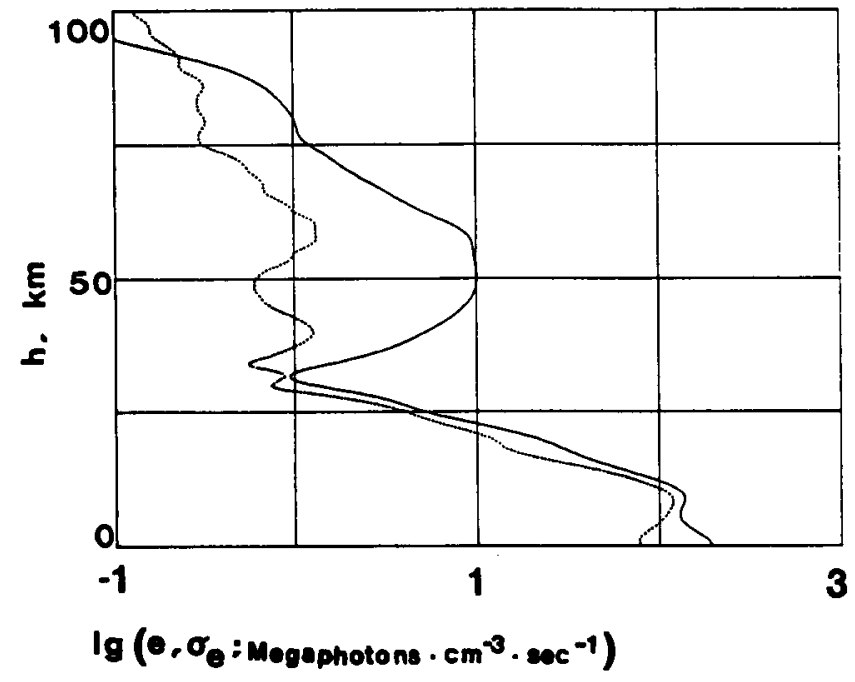

Figure 3. The mean volume emission rate e of the molecular oxygen at the wavelength $1.7 \mu \mathrm{m}$ (continuous line) and its standard deviation $\sigma_{e}$ (dotted line), as the functions of height $h$ in the latitude interval $0-50^{\circ} \mathrm{S}$ on 22 October 1985.

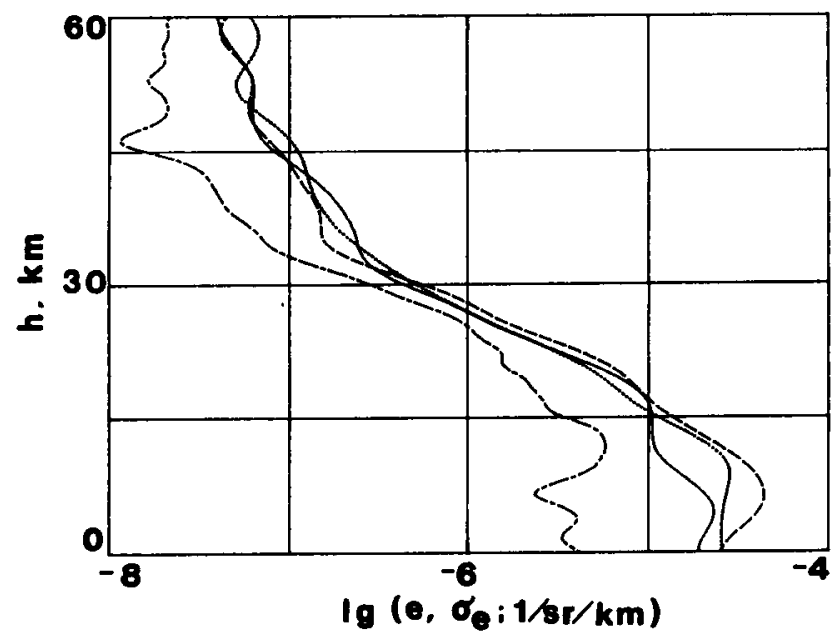

Figure 4. The relative volume emission rate $e_{\lambda}(h)=E_{\lambda}(h) / C_{\lambda}\left(E_{\lambda}\right.$ is the volume emission coefficient, $C_{\lambda}$ is the spectral solar constant) at the wavelength $0.84 \mu \mathrm{m}$ on 22 October 1985. $-0-5^{\circ} \mathrm{S} ; \ldots . .-10-15^{\circ} \mathrm{S} ; . . .--20-25^{\circ} \mathrm{S} ;$-.....- - the standard deviation of the relative volume emission rate for $20-25^{\circ} \mathrm{S}$. 